\title{
Hearts with one ventricle: current concepts and management
}

\author{
I D SULLIVAN AND J F N TAYLOR \\ Cardiothoracic Unit, The Hospital for Sick Children, Great Ormond Street, London
}

\section{Nature of the problem}

Many congenital cardiac malformations result in a heart with only one effective ventricle. In most of these there is a second ventricle present, but it is too small to sustain cardiac output making construction of a biventricular circulation impossible. These hearts may be classified according to the atrioventricular connection. There are two possibilities: the atria are each connected to a separate ventricle, or the atria are connected to only one ventricle.

When each of the atria is connected separately to one of two ventricles, either ventricle may be too small. The right ventricular cavity is small in almost all cases of pulmonary atresia with intact ventricular septum, and in some hearts in which the tricuspid valve straddles a ventricular septal defect. A small left ventricular cavity is the hallmark of the hypoplastic left heart syndrome.

When the atria are connected to only one ventricle (irrespective of the possible presence of another rudimentary ventricle) there is a 'univentricular atrioventricular connection' ${ }^{1}{ }^{2}$ If both atria are connected to one ventricle, it is termed 'double inlet' ventricle. There are usually two atrioventricular valves under these circumstances but sometimes a common atrioventricular orifice drains both atria. Alternatively, one atrioventricular connection may be absent (fig 1). In tricuspid atresia the right atrioventricular connection is absent. Systemic venous return to the right atrium has an obligatory flow across the atrial septum into the left atrium and together with pulmonary venous blood passes to the left ventricle through the mitral valve. There is obligatory transatrial flow of pulmonary venous blood in the opposite direction (from left atrium to right atrium) in hearts in which the mitral valve is atretic or the left atrioventricular connection absent. A valve is atretic if it is formed but imperforate; the atrioventricular connection is absent if there is no valve tissue at all.
Although these malformations are comparatively rare, tricuspid atresia, double inlet ventricle, and hypoplastic left heart syndrome each accounted for nearly $5 \%$ of the total number of symptomatic infants with congenital heart disease in a British survey of the decade preceding $1982 .{ }^{3}$ In addition, about a third of those patients with double inlet ventricle will present after infancy (Franklin RCG, Deanfield JE, Anderson RH, et al, unpublished observations).

\section{Presentation}

The nature of the ventriculoarterial connection and the degree of obstruction to pulmonary or systemic outflow will determine the clinical presentation. Symptoms of heart failure caused by high pulmonary blood flow develop as the pulmonary vascular resistance falls in early infancy if neither pulmonary nor systemic ventricular outflow is obstructed. Obstruction to systemic or pulmonary blood flow is common. The obstruction may occur at the pulmonary or the aortic valve, but more often is the result of subvalvular muscular narrowing, either just below the valve, or less often at a restrictive ventricular septal defect when one great artery arises from a rudimentary ventricle. It is rare for a child to be born with obstruction to both systemic and pulmonary blood flow.

Mild to moderate 'pulmonary stenosis' may regulate pulmonary blood 'appropriately'. The balanced haemodynamic state that results may be compatible with survival into adult life with minimal symptoms. Severe 'pulmonary stenosis' causes low pulmonary blood flow with cyanosis. Hypercyanotic episodes, similar to those classically associated with tetralogy of Fallot, may occur when there is a dynamic element to the subpulmonary obstruction. Under extreme circumstances, in which the pulmonary outflow is atretic at birth, pulmonary blood flow 


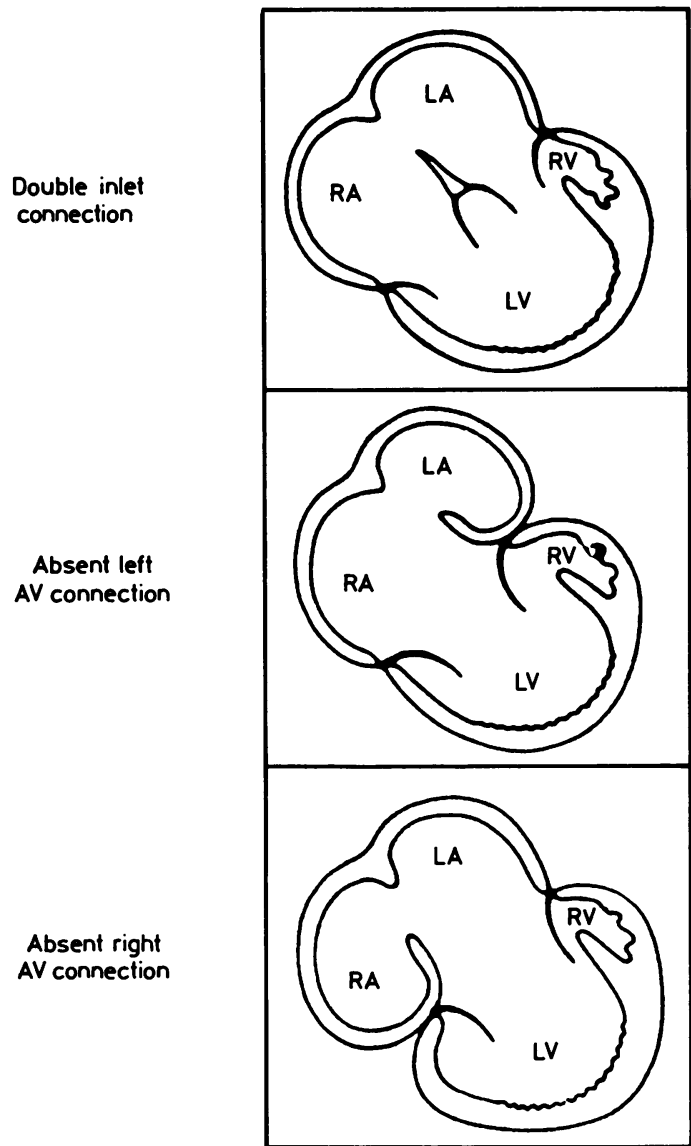

Fig 1 Simplified diagram of atrioventricular connections that may occur in univentricular atrioventricular connection to a morphological left ventricle. (Adapted by permission of MTP Press Ltd, Lancaster. $\left.{ }^{\prime}\right)$ AV =atrioventricular; $L A=$ left atrium; $L V=$ left ventricle; $R A=$ right atrium; $R V=$ right ventricle.

is precarious as it is dependent on the persistence of the ductus arteriosus.

Obstruction to the systemic outflow results in the particularly adverse combination of low systemic blood flow and high pulmonary blood flow; early neonatal heart failure is usually the result. Systemic outflow obstruction in hearts with either a double inlet ventricle or an absent atrioventricular connection occurs typically when the aorta arises from a rudimentary subaortic ventricle. If this is the case, after the duct has closed the total systemic blood flow must pass through the ventricular septal defect and small subaortic chamber, both of which are potential sites for subaortic stenosis (fig 2). The common addition of coarctation of the aorta to the anomaly gives a dismal prognosis with conventional surgical management (Franklin RCG, Deanfield JE, Anderson RH, et al, unpublished observations).$^{4}$ If there is complete obstruction to systemic outflow from the heart, systemic perfusion will be totally dependent on right to left ductal shunting; this is usual in hypoplastic left heart syndrome. Perfusion of the head and neck vessels together with the coronary arteries becomes reliant on retrograde flow into the hypoplastic ascending aorta from the duct. Ductal closure is, of course, fatal.

\section{Palliative surgery}

Most children with double inlet ventricle or tricuspid

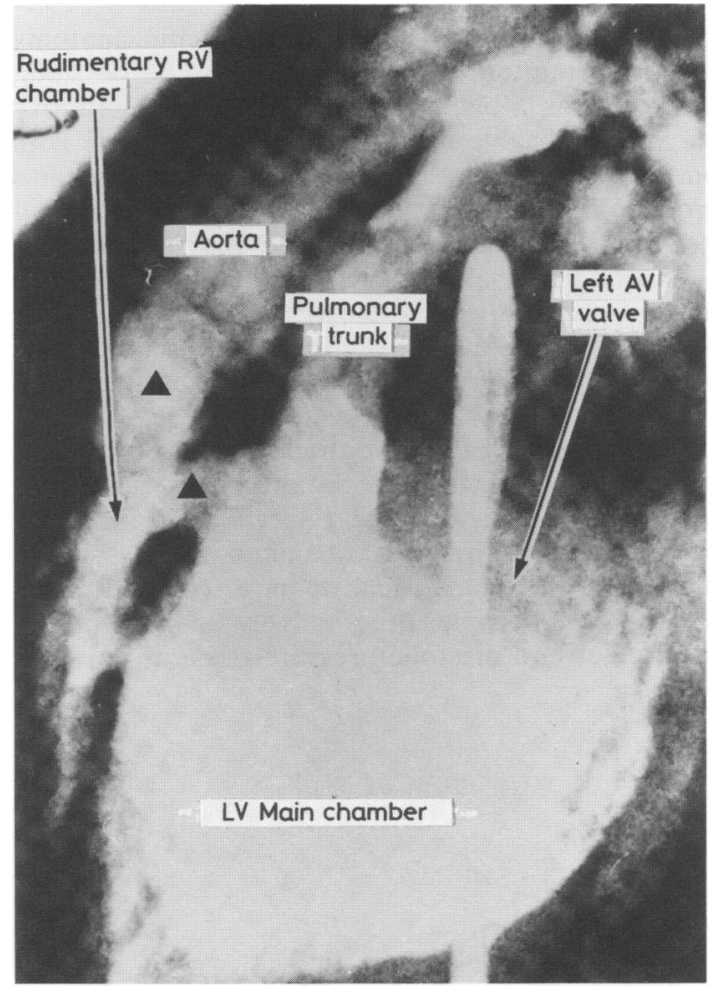

Fig 2 Lateral angiocardiogram from a patient with absent right atrioventricular connection and ventriculoarterial discordance (tricuspid atresia with transposition of the great arteries). The aorta arises anteriorly from the rudimentary right ventricle. The subaortic infundibulum and the ventricular septal defect (arrowheads), are potential sites for subaortic obstruction. (Adapted with permission from Pediatric Cardiology. $\left.{ }^{2}\right) A V=$ atrioventricular; $L V=$ left ventricle; $R V=$ right ventricle. 
atresia will require palliative surgery in infancy to survive (Franklin RCG, Deanfield JE, Anderson $\mathrm{RH}$, et al, unpublished observations). ${ }^{4}$ Most commonly this will consist of either a systemic to pulmonary artery shunt to augment inadequate pulmonary blood flow, or a pulmonary artery band to diminish excessive pulmonary blood flow. Although palliative surgery may ensure immediate survival, about half of those with tricuspid atresia die by the age of 5 years, and two thirds by the age of 20 years. $^{5}$ The rate of survival after palliative surgery for double inlet ventricle is similar (Franklin RCG, Deanfield JE, Anderson RH, et al, unpublished observations). Consequently, definitive surgery will be required for these patients to survive childhood.

\section{Definitive surgery: the Fontan circulation}

In a few exceptional cases with specific anatomy surgical septation of the ventricle may be possible, thus creating a biventricular circulation. Definitive surgery applicable to a wider group of hearts with one ventricle was first performed by Fontan's group. ${ }^{6}$ This novel surgical approach has revolutionised management. It established the feasibility of connecting the pulmonary and systemic circulations in series with only one-the systemic-ventricle (fig $3)$. This is achieved by connecting the systemic venous return directly to the pulmonary arterial circuit.

How can the solitary ventricle power both systemic and pulmonary circulations in series? The physiology underlying the Fontan circulation has been described in lucid yet comparatively simple terms by Bull. ${ }^{7}$ In a normally connected heart, if the left ventricle becomes progressively smaller, the left ventricular end diastolic pressure rises, as does the left atrial and pulmonary venous pressure; the eventual consequence is pulmonary oedema. In contrast, if the right ventricle becomes progressively smaller, the right ventricular end diastolic pressure rises as does right atrial pressure. Eventually (provided pulmonary vascular resistance is low) right atrial pressure will exceed pulmonary artery pressure, and may be transmitted directly. This assumes that the right ventricle serves as a passive conduit and does not cause obstruction to flow. Blood may then flow from the right atrium to the pulmonary artery without any augmentation of flow from the right ventricle. Under these circumstances the circulation may be maintained 'without' the right ventricle at the expense of a high systemic venous pressure. The maintenance of a low systemic venous pressure is the function of the right ventricle under normal circumstances.

The same concept permits the circulation to 'work' when systemic venous return is connected directly to the pulmonary arteries in the absence of a right ventricle. Specific criteria must be fulfilled, however. The most important of these are that pulmonary vascular resistance is low without distortion of the pulmonary arteries, ${ }^{8}$ and that the single ventricle has well preserved function. If ventricular function is poor or there is atrioventricular valve regurgitation, ventricular end diastolic pressure and left atrial pressure will be raised. The systemic venous pressure necessary to sustain a Fontan circulation will then be raised so high that oedema, ascites, and pleural effusions will accumulate. It is not surprising, therefore, that ventricular hypertrophy (which will increase ventricular 'stiffness') is an adverse risk factor for the success of a Fontan operation, even when the above criteria are fulfilled. ${ }^{9}$ The systemic venous pressure measured early in the postoperative period is a reliable
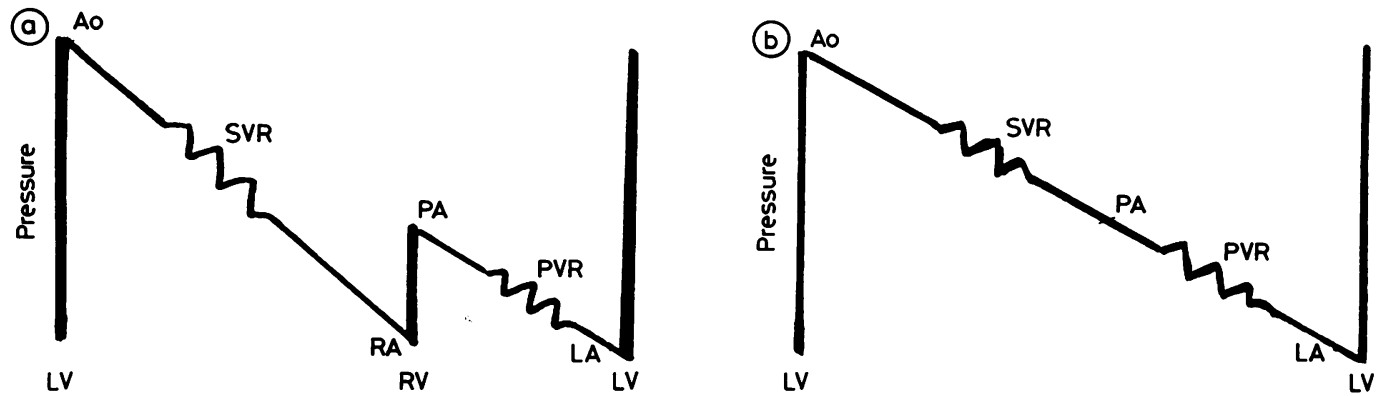

Fig 3 Schematic representation of the resistances encountered in (a) the normal circulation, (b) the Fontan circulation, with bypass of the right heart. (Reproduced by permission of MTP Press Ltd, Lancaster. ${ }^{7}$ ) Ao=aorta; PA=pulmonary artery; $P V R=$ pulmonary vascular resistance; $S V R=$ systemic vascular resistance; $R A=$ right atrium; $L A=$ left atrium; $L V=$ left ventricle; $R V=$ right ventricle. 
predictor of a good result after a Fontan operation. There is a rapid increase in the probability of early death if the mean pressure exceeds $15 \mathrm{~mm} \mathrm{Hg} .{ }^{9}$

The original Fontan operation was described for the treatment of classical tricuspid atresia and incorporated a valved conduit between the right atrium and pulmonary artery. ${ }^{6}$ Since then numerous modifications of the procedure have been undertaken and the concept extended to the wider range of cardiac malformations described above. Direct right atrial to pulmonary artery connections became fashionable when it was shown that a valve between right atrium and pulmonary artery was unnecessary. ${ }^{7}$ The most recent development has been to connect the systemic veins rather than the right atrium to the pulmonary artery, creating total cavopulmonary rather than atriopulmonary connection. ${ }^{10}$ This requires a channel within the right atrium directing inferior vena caval and hepatic venous blood to the pulmonary artery, while a direct anastomosis is made between the superior vena cava and the pulmonary artery (fig 4). There are a number of potential advantages. Flow disturbance to systemic venous return in the large capacity right atrium is avoided. The right atrium is not distended and hypertensive, which is inevitably the case with atriopulmonary connection, thereby possibly reducing the risk of late supraventricular arrhythmias.
The coronary sinus continues to drain into the low pressure atrium and thence into the ventricle, together with pulmonary venous blood. Maintenance of this low pressure outlet for coronary sinus blood flow may have important beneficial effects on long term ventricular function. ${ }^{11}$ Total cavopulmonary connection is of particular advantage in mitral atresia, or when a common atrioventricular valve forms the double inlet univentricular connection, or in defects with bilateral superior venae cavae.

\section{Management considerations}

Current management should be directed at giving the infant whose heart has one ventricle the best chance of a successful Fontan procedure. Palliative surgery in the neonatal period or early infancy is no longer required merely for survival or symptoms, but should be considered as preparation for an anticipated Fontan procedure. Care must be taken not to distort pulmonary artery anatomy if a palliative systemic to pulmonary artery shunt is required. On the other hand, when there is high pulmonary blood flow at high pressure the lungs should be protected from development of even mild pulmonary arteriolar thickening because maintenance of low pulmonary vascular resistance is crucial. ${ }^{8}$ The conventional palliative operation car-
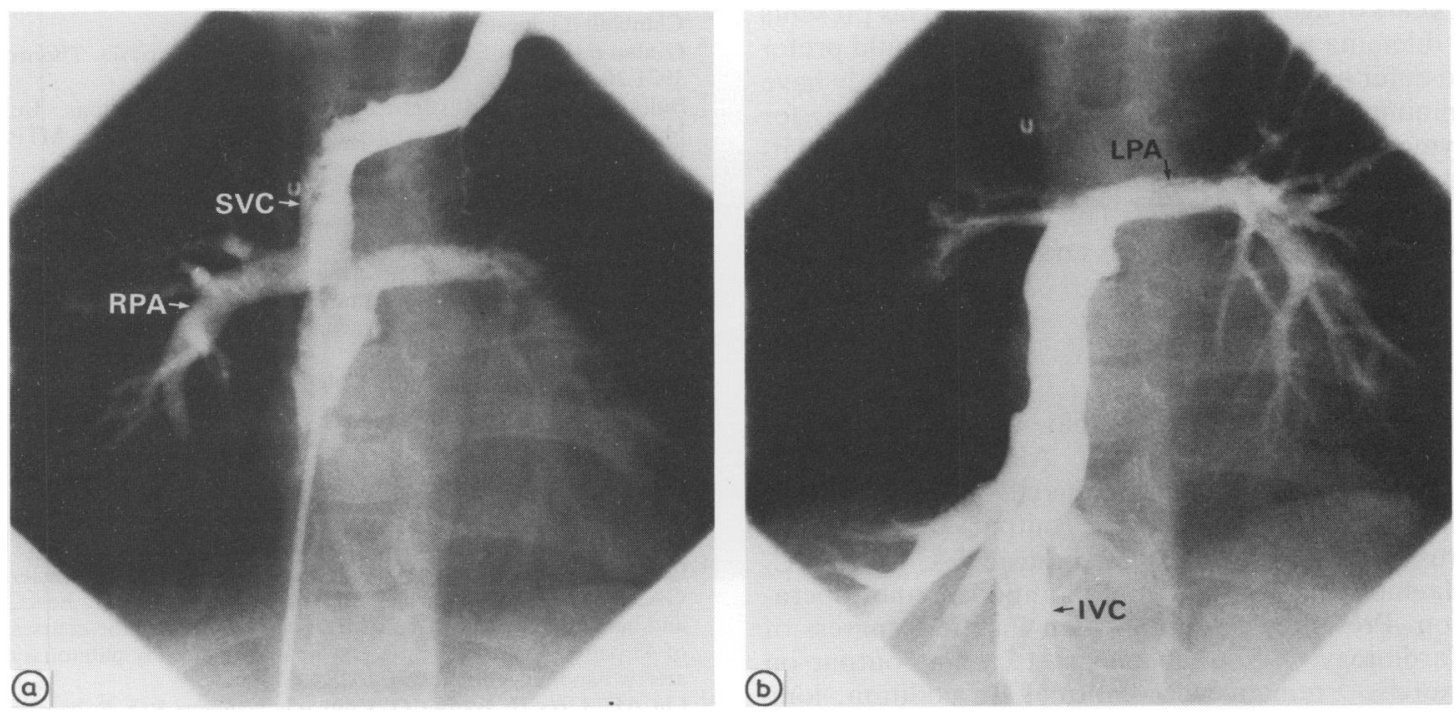

Fig 4 Anteroposterior angiocardiograms showing a total cavopulmonary connection: (a) injection of contrast into superior vena cava, which has been anastomosed to the right pulmonary artery; (b) injection of contrast into the inferior vena cava, showing drainage of inferior vena caval and hepatic venous blood through a channel in the right atrium, which is connected to the pulmonary artery with the stump of the previously transected superior vena cava. IVC=inferior vena cava; $L P A=$ left pulmonary artery; $R P A=$ right pulmonary artery; $S V C=$ superior vena cava. 
ried out under these circumstances has been pulmonary artery banding, but initial palliation by pulmonary artery banding has been associated with an unacceptably high incidence of development of subaortic stenosis in the presence of a rudimentary subaortic ventricle (fig 2$)^{12}$ although the problem may be largely confined to those infants who also have coarctation of the aorta (Franklin RCG, Deanfield JE, Anderson RH, et al, unpublished observations). ${ }^{4}$ The combination of obstruction to pulmonary outflow from the pulmonary artery band together with developing systemic outflow obstruction is a potent stimulus to hypertrophy of the dominant ventricle, and mitigates against the success of an eventual Fontan procedure. Consequently, it seems that more aggressive surgery in early infancy may be necessary if the long term outlook of this group is to be improved. A direct pulmonary artery to ascending aortic connection can bypass the existing or potential area of subaortic obstruction, with pulmonary blood flow secured by means of a systemic to pulmonary shunt. ${ }^{13-15}$ The nature of this palliative approach is similar to the one used in the management of the hypoplastic left heart syndrome. ${ }^{16}$ The aim of all these palliative procedures is to prepare the circulation for a definitive Fontan type of operation at a later date.

The concern about ventricular hypertrophy as an adverse risk factor has led to recommendations that the definitive procedure should be performed at 2 or 3 years of age in suitable candidates. ${ }^{89}$ This presents a dilemma to clinicians, most of whom would prefer to defer high risk surgery for children who only have minimal symptoms. The risk inherent in waiting for symptomatic deterioration, however, is the inevitable progression of ventricular hypertrophy in a volume loaded ventricle. This will increase the risk of the definitive operation and prejudice the functional result.

\section{Conclusions}

How well are children who have had a 'good' result from a Fontan operation? Although many are apparently asymptomatic, objective assessment has shown that resting cardiac output (Knight WB, Busst CM, Rigby ML, Shinebourne EA, Lincoln C. Haemodynamics following modified Fontan operation. Presented at Ninth Asian Pacific Congress of Cardiology, 1987) and maximal cardiac output on exercise $^{17}$ remain below normal. In addition, long term follow up information is lacking about the effect of persistently raised systemic venous pressure and its diminished flow velocity, the possible deterioration in ventricular function with time, and the development of arrhythmias. Children with
Fontan circulations are also inevitably at increased risk when intercurrent respiratory infections cause increases in pulmonary vascular resistance that would be unimportant to a normal heart.

Definitive surgery is now available, however, to many children with complex congenital heart disease who were previously considered inoperable. Despite these reservations, the results in the first decade after the introduction of this unique surgical approach have been encouraging. Concurrent rapid advances have occurred in the fields of heart and heart/lung transplantation. These offer an alternative form of definitive surgery for children who are unsuitable for, or who have had a poor result from, a Fontan type of operation.

\section{References}

1 Anderson RH, Ho SY. The diagnosis and naming of congenitally malformed hearts. In: Macartney FJ, ed. Congenital heart disease. Lancaster: MTP Press, 1986:1-34.

2 Anderson RH, Macartney FJ, Tynan M, et al. Univentricular atrioventricular connexion-the single ventricle trap unsprung. Pediatr Cardiol 1983;4:273-80.

3 Scott DJ, Rigby ML, Miller GAH, Shinebourne EA. The presentation of symptomatic heart disease in infancy based on 10 years' experience (1973-82). Br Heart J 1984;52:248-57.

4 Franklin RCG, Sullivan ID, Thoele DE, Macartney FJ, Anderson RH, Deanfield JE. Fate of children with tricuspid atresia presenting in infancy. Br Heart $J$ 1988;59:122.

5 Anderson RH, Macartney FJ, Shinebourne EA, Tynan M, eds. Tricuspid atresia. In: Paediatric cardiology. Vol 2. London: Churchill Livingstone, 1987:675-96.

6 Fontan F, Baudet E. Surgical repair of tricuspid atresia. Thorax 1971;26:240-8.

7 Bull C. Atrial and ventricular dependent circulations. In: Macartney FJ, ed. Congenital heart disease. Lancaster: MTP Press, 1986:35-53.

8 Mayer JE, Helgason H, Jonas RA, et al. Extending the limits for modified Fontan procedures. J Thorac Cardiovasc Surg 1986;92:1021-8.

9 Kirklin JK, Blackstone EH, Kirklin JW, Pacifico AD, Bargeron LM, Jr. The Fontan operation. Ventricular hypertrophy, age, and date of operation as risk factors. J Thorac Cardiovasc Surg 1986;92:1049-64.

10 de Leval M, Bull C, Kilner P. Total cavopulmonary connection, a logical alternative to atriopulmonary connection for complex Fontan operations. Experimental studies and early clinical experience. J Thorac Cardiovasc Surg 1988 (in press).

11 Ilbawi MN, Idriss FS, Muster AJ, et al. Effects of elevated coronary sinus pressure on left ventricular function after the Fontan operation. J Thorac Cardiovasc Surg 1986;92:231-7.

12 Freedom RM, Benson LN, Smallhorn JF, Williams WG, Trusler GA, Rowe RD. Subaortic stenosis, the univentricular heart, and banding of the pulmonary artery: an analysis of the courses of 43 patients with univentricular heart palliated by pulmonary artery banding. Circulation 1986;73:758-64.

13 Lin AE, Laks H, Barber G, Chin AJ, Williams RG. Subaortic obstruction in complex congenital heart disease: management by proximal pulmonary artery to ascending aorta end to side anastomosis. J Am Coll Cardiol 1986;7:617-24.

14 Rothman A, Lang P, Lock JE, Jonas RA, Mayer JE, Castaneda AR. Surgical management of subaortic obstruction in single left ventricle and tricuspid atresia. J Am Coll Cardiol 1987;10:421-6. 
15 Freedom RM. The dinosaur and banding of the main pulmonary trunk in the heart with functionally one ventricle and transposition of the great arteries: a saga of evolution and caution. J Am Coll Cardiol 1987;10:427-9.

16 Jonas RA, Lang P, Hansen D, Hickey P, Castaneda AR. 1ststage palliation of hypoplastic left heart syndrome: the importance of coarctation and shunt size. $J$ Thorac Cardiovasc Surg 1986;92:6-13.
${ }^{17}$ Driscoll DJ, Danielson GK, Puga FJ, Schaff HV, Heise CT, Staats BA. Exercise tolerance and cardiorespiratory response to exercise after the Fontan operation for tricuspid atresia or functional single ventricle. J Am Coll Cardiol 1986;7:1087-94.

Correspondence to $\mathrm{Dr}$ I Sullivan, Cardiothoracic Unit, The Hospital for Sick Children, Great Ormond Street, London WC1N 3JH. 